\title{
Geographical patterns of genetic subdivision in the cellar spider Pholcus phalangioides (Araneae)
}

\author{
MARTIN A. SCHÄFER $\dagger$, AXEL HILLE $+\&$ GABRIELE B. UHL*† \\ $\dagger$ Institut für Zoologie, Abteilung Ethologie, Kirschallee 1, D-53115 Bonn, Germany and $\ddagger$ Forschungsinstitut und \\ Museum Alexander Koenig, Adenauerallee 160, D-53113 Bonn, Germany
}

\begin{abstract}
Geographical patterns of gene flow and drift were analysed in the commensal cellar spider Pholcus phalangioides to get insight into the causes affecting genetic variation in this species strictly associated with man. Our sampling consisted of 23 subpopulations collected over five urban regions in central Europe (distances ranged from $920 \mathrm{~km}$ to sites within the same building complex). Five variable allozyme loci showed significant interpopulation subdivision $(\theta=0.146)$ and isolation by distance over the area studied. On a regional scale (up to $70 \mathrm{~km}$ ) significant differentiation was found, but the genetic pattern did not correlate with distance. Moreover, significant two-locus disequilibria were detected and a recent reduction in the effective population size was indicated within six sites. These results suggest that in $P$. phalangioides a high potential of dispersal and strong effects of drift within small, demographically unstable mating units seem to cause significant, but unpredictable genetic differentiation patterns at lower geographical scales. Our study documents strong effects of drift in a strictly commensal species outside the murine rodents.
\end{abstract}

Keywords: allozymes, bottleneck effect, dispersal, drift, gene flow, genetic differentiation, geographical separation.

\section{Introduction}

If selection and mutation rates are low, the degree of genetic differentiation between populations reflects a balance among the constraining forces of gene flow and genetic drift (Slatkin, 1987, 1993). Thus, intraspecific modes of dispersal fundamentally influence a species' population structure. In species with a high potential for long-distance dispersal, the genetic structure is expected to be homogeneous throughout a large geographical area. In contrast, low mobility causes significant genetic differences between populations and a significant pattern of isolation by distance at migration-drift equilibrium (Slatkin, 1993).

However, populations of many species are divided into small mating units which often fluctuate in size or may be subject to extinction and recolonization (Whitlock, 1992). In such demographically unstable populations the migration-drift equilibrium will only be reached, if the conditions conducive to dispersal remain sufficiently stable for a long enough time (Hutchinson \& Templeton, 1999). A nonequilibrium population struc-

*Correspondence. E-mail: g.uhl@uni-bonn.de ture on a lower geographical scale is likely for many taxa, either because the required conditions are not met, or the populations have not existed long enough to exhibit a significant pattern of isolation by distance (McCauley, 1993).

Although many studies have investigated the influence of geographical separation on the degree of population differentiation, most of them do not explicitly address the geographical scale of gene flow. Evaluating patterns of population differentiation at different spatial scales provides the opportunity to gain additional important information about the relative influences of dispersal and genetic drift (see Hutchinson \& Templeton, 1999). In spiders, for example, there exists only a single study on patterns of isolation by distance at different geographical scales (Johannesen et al., 1998).

The cosmopolitan cellar spider Pholcus phalangioides (Fuesslin, 1775) provides an interesting species with which to investigate the migration-drift equilibrium at different spatial scales. In temperate climates its habitats are strongly associated with human buildings (Sacher, 1983; Vanuytven, 1991) possibly leading to discrete habitats and relatively small population sizes. Thus, genetic drift and founder effects are expected to play a 
major role in shaping the population structure in this species. In spite of the omnipresence of the cellar spider little is known about its dispersal abilities. In spiders, active dispersal over short distances occurs by crawling and long-distance dispersal by air ('ballooning') is known for many species. However, pholcids are not cited as ballooning spiders, except for one tropical pholcid (Decae, 1987). If it occurs at all, ballooning is expected to be more important under open field conditions. Similar to other commensal species, the strong coexistence with man suggests that passive long-distance dispersal by man may affect the genetic structure of $P$. phalangioides populations (see also Porter \& Jakob, 1990 for another pholcid spider). Inferring general patterns of dispersal in spiders from interspecific comparison of population structures is limited as there is considerable variation among species. For several web spiders clinal variation in gene frequencies were demonstrated (Cesaroni et al., 1981; Johannesen et al., 1998), whereas the population genetic structure of a coastal dune spider, Geolycosa pikei, does not display any significant variation over a distance of $100 \mathrm{~km}$ (Boulton et al., 1998).

In previous studies little attention has been paid to the population genetic structure of species strictly associated with man, so-called synanthropic species. In this study, we analyse patterns of genetic subdivision in the cellar spider $P$. phalangioides at different geographical scales to get insight into the causes affecting the population genetic structure of a synanthropic species. Our study will provide information on the cellar spiders' potential of dispersal and on how the distribution of genetic variation is influenced by the urban habitat.

\section{Materials and methods}

\section{Sampling sites}

We collected $P$. phalangioides from 23 sites in five urban areas between 1998 and 1999: Amsterdam (Netherlands), Bonn, Konstanz, Düsseldorf (all Germany) and the region around Odder (Denmark). All spider samples

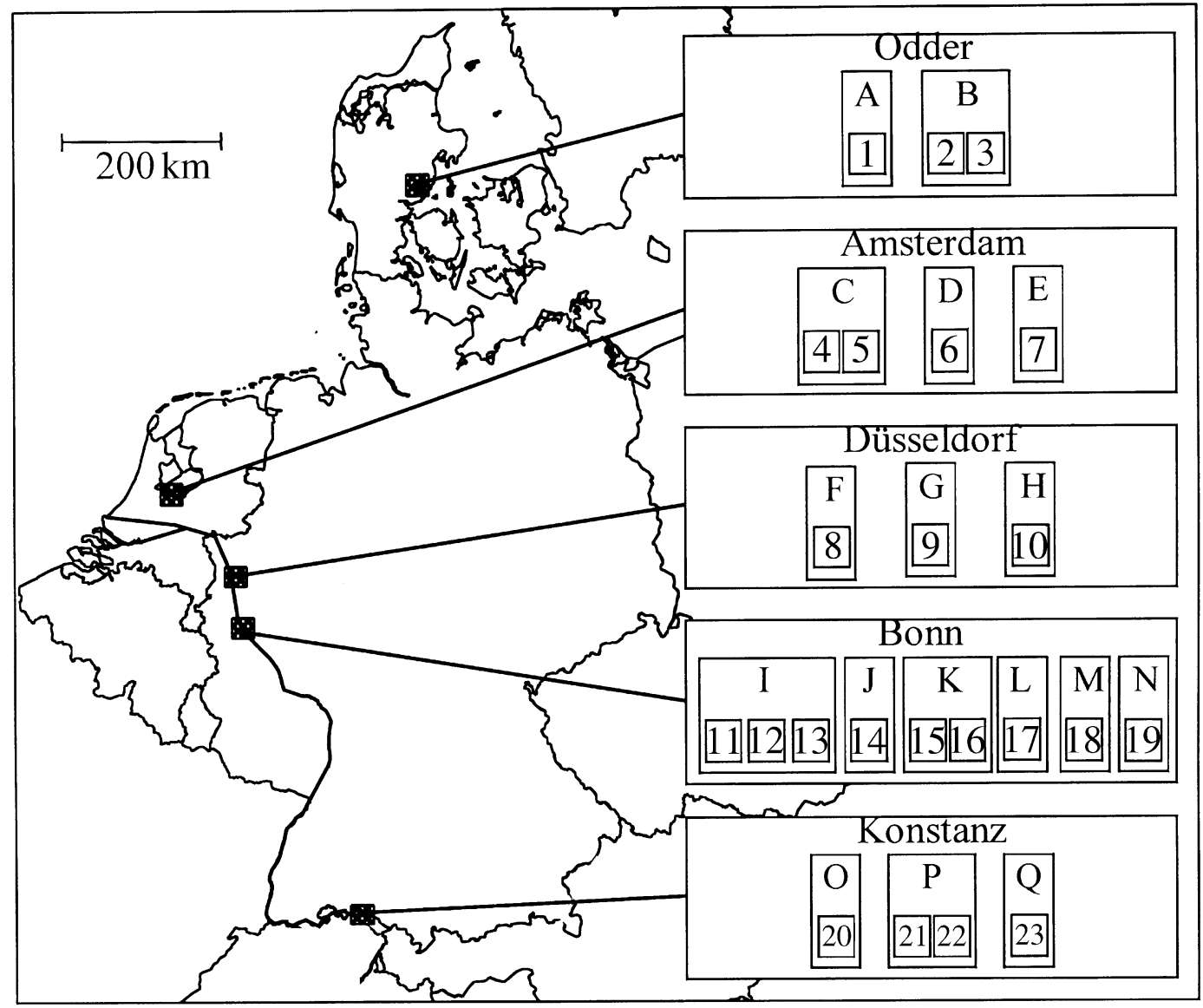

Fig. 1 Map of sampling locations illustrating the three-hierarchical sampling scheme: Level 1: all sampling sites (1-23) in A-Q buildings. Level 2: samples within the five urban regions. Level 3: sample sites of the same building complex.

(c) The Genetics Society of Great Britain, Heredity, 86, 94-102. 
were collected in parts of buildings like cellars, garages, dwellings, or corridors of museums and universities. Our sampling arrangement of the locations with hierarchical levels classified is presented in Fig. 1. To determine the fine-scale genetic substructuring at a within-building level, samples were taken from single rooms. Samples consisted of 17 individuals on average, ranging from 12 to 24 (Table 1). Spiders were brought to the laboratory and stored at $-80^{\circ} \mathrm{C}$ until they were processed for enzyme electrophoresis. Electrophoretically analysed sample sizes for monomorphic loci were lower, but at least five individuals per sample were investigated.

\section{Electrophoresis}

Vertical starch gel electrophoresis was employed, using $12 \%$ starch gels (Biomol, Hamburg). Individual spiders were homogenized in $75 \mu \mathrm{L}$ of homogenization buffer $(0.1 \mathrm{M}$ Tris- $\mathrm{HCl}$ containing $0.002 \mathrm{M}$ EDTA and $0.05 \mathrm{M}$ NADP) and centrifuged at $12000 \mathrm{~g}$ for $3 \mathrm{~min}$.
A total of 19 enzyme systems encoded for by 26 loci were scored: Aat-1,-2 (EC 2.6.1.1), Acon-1,-2 (EC 4.2.1.3), Ald (EC 4.1.2.13), Alpdh (EC 1.5.1.17), Fum (EC 4.2.1.2), Gpdh (EC 1.1.1.8), Gpt (EC 2.6.1.2), $H k$ (EC 2.7.1.1), Idh-1,-2 (EC 1.1.1.42), Ldh-1,-2 (EC 1.1.1.27), Mdh-1,-2 (EC 1.1.1.37), Np (EC 2.4.2.1), Pep1,-2 (EC 3.4.11), 6-Pgd (EC 1.1.1.44), Pgi (EC 5.3.1.9), Pgm (EC 2.7.5.1), Pk-1,-2 (EC 2.7.1.40), Sod (EC 1.15.1.1) and Sordh (EC 1.1.1.14). In order to stain peptidases we used five substrates (N-acetyl-L-methionine, leucine-glycine-glycine, leucine- $\beta$-alanine, H-leucine-alanine-OH and leucine- $\beta$-naphthylamide), but only two loci could be detected satisfactorily and were included in the analysis. Three different buffer systems were used: continuous Tris-Citrate $\mathrm{pH}=7.5$ (Harris \& Hopkinson, 1978) for Acon, Idh, Ldh, Mdh, Np, 6-Pgd, $P g i$, Pgm; discontinuous Tris-Borate $\mathrm{pH}=8.2$ (Poulik, 1957) for Ald, Alpdh, Gpt, Gpdh, Pep; and discontinuous Lithium-Borate $\mathrm{pH}=8.1$ (Selander et al., 1971) for Aat, Fum, Hk, Pk, Sod, Sordh. Staining recipes followed references in Harris \& Hopkinson (1978) and Hillis \&

\begin{tabular}{|c|c|c|c|c|}
\hline Population & $N$ & $\begin{array}{l}\text { Two-locus } \\
\text { disequilibria }\end{array}$ & $\begin{array}{c}\text { Number of } \\
\text { loci }\left(H_{\mathrm{e}}>H_{\mathrm{eq}}\right) / \text { loci } \\
\text { polymorphic }\end{array}$ & $\begin{array}{c}P \text { for } \\
H_{\mathrm{e}}>H_{\mathrm{ec}}\end{array}$ \\
\hline 1 & 20 & Acon $-2 / N p^{* *}$ & $3 / 5$ & 0.313 \\
\hline 2 & 19 & None & $4 / 5$ & 0.109 \\
\hline 3 & 18 & Acon- $1 /$ Acon $-2 *$ & $2 / 5$ & 0.594 \\
\hline 4 & 15 & Acon $-1 / N p^{* * * \mathrm{~B}}$ & $3 / 4$ & 0.094 \\
\hline 5 & 19 & None & $2 / 4$ & 0.156 \\
\hline 6 & 17 & Acon-2/6-Pgd* & $3 / 3$ & 0.063 \\
\hline 7 & 14 & Acon-1/Sordh* & $3 / 5$ & 0.313 \\
\hline 8 & 24 & None & $2 / 5$ & 0.5 \\
\hline 9 & 22 & $\begin{array}{l}\text { Acon- } 1 / \text { Acon-2*, } \\
\text { Acon- } 1 / \text { Sordh } * * \\
\text { Acon }-2 / \text { Sordh } *{ }^{*} \mathrm{~B}\end{array}$ & $2 / 4$ & 0.563 \\
\hline 10 & 15 & None & $2 / 4$ & 0.156 \\
\hline 11 & 19 & None & $2 / 4$ & 0.156 \\
\hline 12 & 12 & None & $4 / 4$ & $0.031 *$ \\
\hline 13 & 18 & Acon $-2 / N p^{*}$ & $4 / 4$ & $0.031 *$ \\
\hline 14 & 15 & $\begin{array}{l}\text { Acon }-1 / \operatorname{Sordh}^{* * * \mathrm{~B}}, \\
\text { Acon }-2 / N p^{* *}\end{array}$ & $4 / 4$ & $0.031 *$ \\
\hline 15 & 17 & $\begin{array}{l}\text { Acon-1/Np*, } \\
\text { Acon-2/Sordh }{ }^{* * \mathrm{~B}}\end{array}$ & $2 / 5$ & 0.5 \\
\hline 16 & 14 & None & $4 / 4$ & $0.031^{*}$ \\
\hline 17 & 15 & Acon-1/Sordh ${ }^{* * \mathrm{~B}}$ & $4 / 4$ & $0.031 *$ \\
\hline 18 & 18 & None & $3 / 4$ & 0.063 \\
\hline 19 & 12 & Acon $-1 / N p^{*}$ & $3 / 4$ & 0.063 \\
\hline 20 & 24 & Acon-1/Sordh** & $4 / 4$ & $0.031^{*}$ \\
\hline 21 & 14 & 6-Pgd/Sordh** & $4 / 5$ & 0.078 \\
\hline 22 & 23 & Acon-2/Sordh* & $3 / 4$ & 0.063 \\
\hline 23 & 18 & None & $3 / 4$ & 0.063 \\
\hline
\end{tabular}

Table 1 Mean number of individuals sampled $(N)$, two-locus linkage disequilibria, ratio of the number of loci that show a higher expected heterozygosity $\left(H_{\mathrm{e}}\right)$ than expected for a mutation-drift equilibrium model $\left(H_{\text {eq }}\right)$ to the number of loci polymorphic, and $P$-values of onesided Wilcoxon sign-rank tests for $H_{\mathrm{e}}>H_{\mathrm{eq}}$ in 23 Pholcus phalangioides populations

$* P<0.05, * * P<0.01, * * * P<0.001)$.

${ }^{\mathrm{B}}$ Significant after Bonferroni correction. 
Moritz (1990). Alleles were designed by capital letters according to their increasing mobility: ' $A$ ' for the slowest allele, 'B' for the next, more anodal, allele and so forth. For locus Sordh alleles migrated both cathodally and anodally and alleles were marked with successive letters starting with 'A', the most cathodal. Genotypic interpretation was only done if the observed banding pattern was consistent with the known quaternary structure of the respective enzyme (Harris \& Hopkinson, 1978).

\section{Data analyses}

Genotype frequencies were tested for deviation from Hardy-Weinberg expectations using the Louis \& Dempster (1987) exact test. Two-locus genotypic disequilibria within samples were calculated to evaluate the independence of two-locus genotypes using the module LINKDOS which is included in the software package GENEPOP (version 3.1.d., Raymond \& Rousset, 1995) and sequential Bonferroni correction was applied $(\alpha=0.05, N=3,6,9,10$, nonindependent tests; Rice, 1989). Mean heterozygosity was calculated using Nei's (1978) unbiased estimate $\left(H_{\mathrm{e}}\right)$ with the program BIOsYs-1 (Swofford \& Selander, 1981).

A recent reduction in the effective size of a population results in a higher $H_{\mathrm{e}}$ than expected from a mutationdrift equilibrium model ( $H_{\mathrm{eq}}$, Cornuet \& Luikart, 1996). To investigate whether demographic instability plays a role within $P$. phalangioides populations we tested whether $H_{\mathrm{e}}$ is significantly larger than $H_{\mathrm{eq}}$, using a onesided Wilcoxon sign-rank test (Cornuet \& Luikart, 1996). When the population size is not stable within sites, one might expect that a few populations show a significant difference. Analyses were done using the program BOTTLENECK (Cornuet \& Luikart, 1996) assuming an infinite alleles model (IAM), since most allozyme frequency distributions appear to fit the IAM better than a stepwise mutation model (Luikart et al., 1998).

Genetic subdivision within and between samples was estimated using nonhierarchical $F$-statistics according to Weir \& Cockerham (1984), in which $F$-coefficients are weighted computations of Wright's (1978) fixation indices $\left(F_{\mathrm{IS}}, F_{\mathrm{IT}}\right.$ and $\left.F_{\mathrm{ST}}\right)$ using version 1.2 of F-STAT software (Goudet, 1995). Standard errors of $f=F_{\mathrm{IS}}$, $\mathrm{F}=F_{\mathrm{IT}}$ and $\theta=F_{\mathrm{ST}}$ estimates were calculated by jackknifing per locus over samples and over loci. Global significance was tested by $95 \%$ bootstrap confidence intervals. The proportion of genetic variance distributed among the three geographical levels was quantified by Wright's (1978) hierarchical $F$-statistics using the BIOSYs-1 package.

To investigate the relationship between geographical distance and genetic differentiation among $P$. phalan- gioides populations a Mantel test (Manly, 1991) was performed with matrices of pairwise calculated $\theta /(1-\theta)$ estimates and straight-line geographical distances (ln +1 transformed) following the recommendations of Rousset (1997) for gene flow in a two-dimensional space. Isolation by distance was tested (i) for the total number of samples ( $\theta$ across loci and for individual loci) in order to test if individual loci are affected by geographical separation and (ii) for pairwise pooled samples from different regions and for samples from the region of Bonn ( $\theta$ across loci) to analyse at which geographical distance migration-drift equilibrium is reached.

Spatial autocorrelation analysis (Sokal \& Oden, 1978) was conducted on allele frequency distributions $(n-1$ alleles/locus) as a function of straight line Euclidean distances $[\mathrm{m}]$ between sampling sites given by their Mercator-projected coordinates using the FORTRAN program SAAP 4.3 (Spatial Autocorrelation Analysis Program, Wartenberg, 1985). Distance class intervals were computer-generated by equalizing sample sizes, so that a minimum of 24-26 pairwise Moran's I coefficients (Sokal \& Oden, 1978) could be calculated in each of the 10 distance classes (distance classes: 4, 21, 72, 236, 246, 373, 442, 599, 606, and $917 \mathrm{~km}$ ). Positive values of $I$ significantly larger than the expectation of $\mathrm{E}(I)=-(n-1)-1$ indicate positive spatial autocorrelation, i.e. similarity of allele frequencies of populations separated by spatial distances given for this distance class (Sokal \& Wartenberg, 1983). Dissimilarity of allele frequencies, i.e. negative autocorrelation, results in significant $I$-values at the negative extreme of the range. Spatial genetic structure was easily depicted as a correlogram plotting $I$-values against their respective distance classes. Overall significance of individual correlograms, each constructed from a series of nonindependent $I$-values, was assessed using the sequential Bonferroni correction.

\section{Results}

\section{Within-population structure}

Twenty-one out of 26 loci analysed were fixed for the same allele in all populations. Five loci were polymorphic (95\% criterion) with a total of 15 alleles: Acon-1,-2, $N p, 6-P g d$ and Sordh. Four out of 95 possible cases deviated significantly from Hardy-Weinberg equilibrium, which consistently scattered over loci or samples. This finding is consistent with the fact that there was no indication of inbreeding or further subdivision within samples (mean $f$-value across samples $=0.018 ; 95 \%$ confidence interval from -0.013 to 0.071 ). One population yielded a significant heterozygote excess across loci 
$(f=-0.29 ; P<0.05)$. Analyses of two-locus genotypic disequilibrium revealed 18 significant disequilibria (out of 162 cases), distributed over $14 P$. phalangioides samples (Table 1). After sequential Bonferroni correction five disequilibria within five samples remained significant. Analyses for recent bottleneck effects showed that six populations exhibited a significantly higher $H_{\mathrm{e}}$ than expected at mutation-drift equilibrium (one sided Wilcoxon sign-rank test, d.f. $=1$, for all significant samples $P=0.031$; Table 1). Mean observed heterozygosity for all $P$. phalangioides samples was $H_{\mathrm{o}}=0.064 ; \mathrm{SE}=0.002$ (range 0.046-0.083) and was very close to the expected heterozygosity $\left(H_{\mathrm{e}}=0.065\right.$; $\mathrm{SE}=0.003)$.

\section{Geographical patterns of genetic subdivision}

All frequent alleles were found in all urban regions, but generally rare alleles were lacking in some regions (allele frequency tables will be provided on request). Genetic differentiation among $P$. phalangioides samples was significant (mean $\theta$ across loci $=0.146 ; 95 \%$ confidence interval from 0.073 to 0.189 ; Table 2). Hierarchical $F$-statistics yielded the highest proportions of total genetic variance resulting from genetic differentiation within regions (Table 3 ). About $21 \%$ of the total genetic variance was due to genetic differentiation among samples of different parts of the same building and about $45 \%$ was attributable to differentiation between different buildings of the same city. The remaining $34 \%$ resulted from genetic differences between regions.

To analyse the influence of geographical distance on genetic differentiation among $P$. phalangioides popula- tions, we estimated pairwise $\theta /(1-\theta)$-values and plotted them against pairwise calculated geographical distances (Ln +1 transformed) among locations (Fig. 2). A onesided Mantel test gave a highly significant positive correlation $(P=0.005)$, thus demonstrating isolation by distance over the range of the entire area studied. A significant pattern of isolation by distance was found for three of the five loci (Acon-1, Np, Sordh, $P<0.05)$ and Acon-2 was close to significance $(P=0.07)$. The locus $6-P g d$ showed no pattern of isolation by distance $(P=0.16)$.

Within distances of $70 \mathrm{~km}$ no significant correlation between genetic differentiation and geographical distances was found (Mantel test for samples from Bonn, $P=0.54$; for pooled samples from Bonn and Düsseldorf; $P=0.16$ ), whereas pairwise comparison of samples between all other regions (including distances between 180 and $917 \mathrm{~km})$ yielded a significant relationship $(P<0.05)$.

Spatial autocorrelation analysis demonstrated significant spatial patterning of allele frequencies over the whole sampling area $(P<0.05)$. After applying sequential Bonferroni correction, 22 out of 70 single autocorrelation coefficients were significant. The locus 6-Pgd showed no spatial pattern $(P=1.0)$. Eight autocorrelation coefficients were significantly positive within the first three distance classes, ranging from 3 to $72 \mathrm{~km}$. Eleven significantly negative Moran's $I$ coefficients were calculated throughout the midrange. Moran's I tended to decrease for successive distance classes up to $606 \mathrm{~km}$. In the highest distance class of up to $917 \mathrm{~km}$ three coefficients again gave significantly positive values. Even though none of the correlograms was monotonically decreasing (Fig. 3), all correlograms showed a similar

\begin{tabular}{llll}
\hline Locus & \multicolumn{1}{c}{$f=F_{\mathrm{IS}}$} & \multicolumn{1}{c}{$F=F_{\mathrm{IT}}$} & $\theta=F_{\mathrm{ST}}$ \\
\hline Acon-1 & $-0.028( \pm 0.047)$ & $0.153( \pm 0.057)$ & $0.153( \pm 0.042)$ \\
Acon-2 & $+0.003( \pm 0.061)$ & $0.072( \pm 0.072)$ & $0.068( \pm 0.035)$ \\
$\mathrm{Np}$ & $+0.055( \pm 0.05)$ & $0.252( \pm 0.081)$ & $0.209( \pm 0.077)$ \\
6-Pgd & $+0.204( \pm 0.101)$ & $0.281( \pm 0.115)$ & $0.094( \pm 0.034)$ \\
Sordh & $+0.018( \pm 0.035)$ & $0.158( \pm 0.042)$ & $0.143( \pm 0.03)$ \\
Mean (across loci) & $+0.018( \pm 0.019)$ & $0.162( \pm 0.039)$ & $0.146( \pm 0.028)$ \\
95\% confidence interval & $-0.013-0.071$ & $0.096-0.249$ & $0.073-0.189$ \\
\hline
\end{tabular}

\begin{tabular}{lccc}
\hline $\mathrm{X}-\mathrm{Y}$ & $F_{\mathrm{XY}}$ & $\begin{array}{c}\text { Variance } \\
\text { component }\end{array}$ & $\begin{array}{c}\text { Geographical } \\
\text { distances }\end{array}$ \\
\hline Population - Building & $0.031(21 \%)$ & $0.053(20 \%)$ & $0 \mathrm{~km}$ \\
Building - Region & $0.065(45 \%)$ & $0.121(45 \%)$ & $1-27 \mathrm{~km}$ \\
Region - Total & $0.049(34 \%)$ & $0.095(35 \%)$ & $58-917 \mathrm{~km}$ \\
Population - Total & $0.138(100 \%)$ & $0.27(100 \%)$ & $0-917 \mathrm{~km}$ \\
\hline
\end{tabular}

Table 2 Summary of $F$-statistics according to Weir \& Cockerham (1984) for polymorphic loci of Pholcus phalangioides with standard errors in parenthesis. 95\% confidence intervals are given for mean $F$-coefficients across loci

Table 3 Three-level hierarchical $F$-statistics combined across loci (Wright, 1978) for Pholcus phalangioides samples. Numbers in brackets are percentages 
Fig. 2 Isolation by distance: pairwise estimated $\theta /(1-\theta)$ for Pholcus phalangioides samples plotted against geographical distance $(\mathrm{Ln}+1$ transformed) between sampling sites $\left(y=0.036 x+0.0101 ; r^{2}=0.157\right.$; $P=0.005)$.

Fig. 3 Spatial autocorrelation analysis: single correlograms of Moran's I coefficients for seven alleles and the average correlogram across all alleles related to distance classes in $\mathrm{km}$.
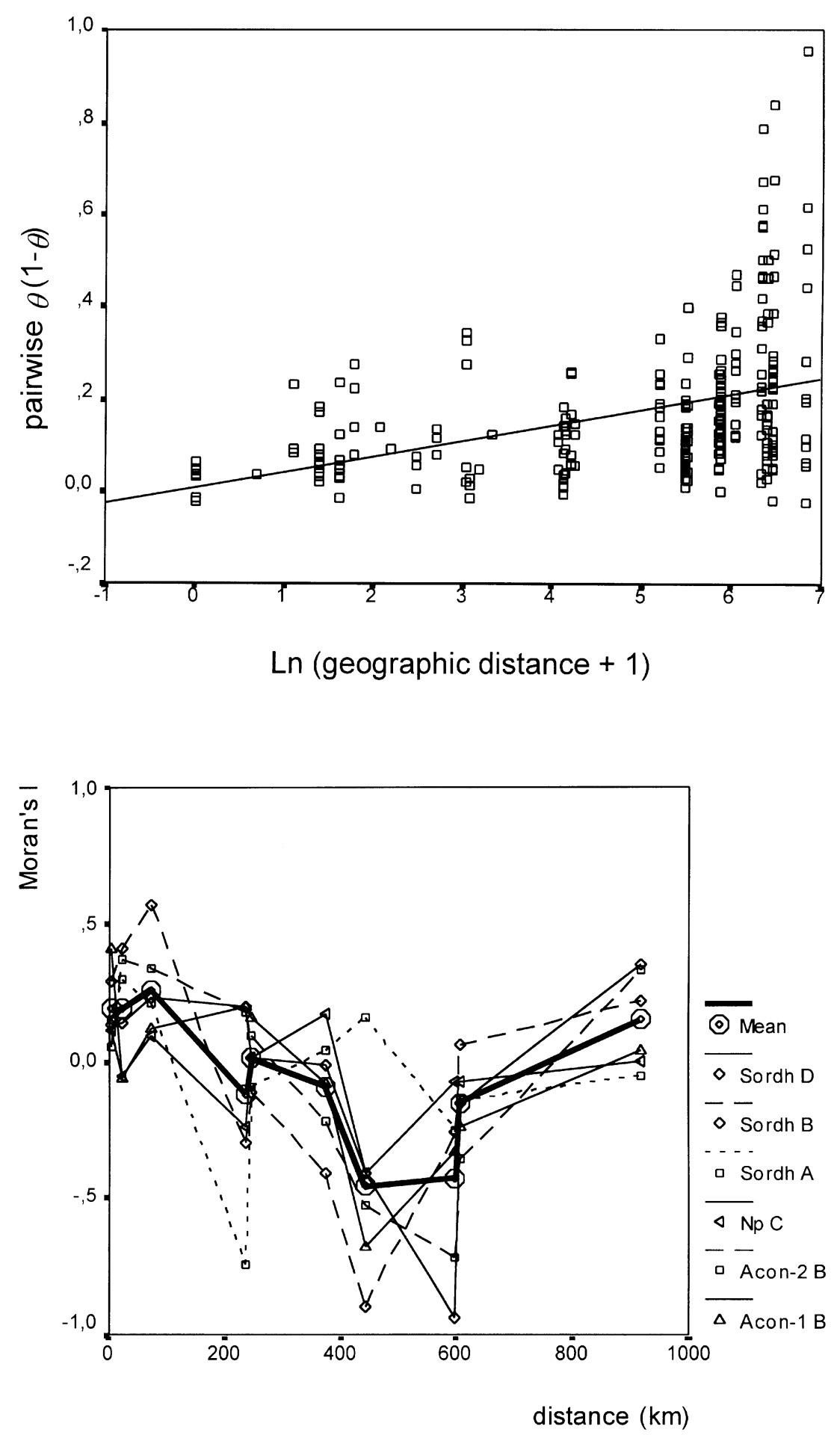

pattern. Thus we used a mean correlogram for the description of the spatial structure of allele frequencies. The distance at which the correlogram first intercepts the abscissa $(\mathrm{E}(I)=0)$ represents the half diameter of a homogeneous distribution of the variable autocorrelated over spatial scales (Sokal \& Oden, 1978). Spatial autocorrelation has been shown to behave as a nonlinear function of neighbourhood size (Sokal \& Jacquez, 1991). The mean correlograms of each of the polymorphic loci indicate that genetic neighbourhood size can be approximately estimated by radial segments of 21-72 $\mathrm{km}$ across the regions sampled. 


\section{Discussion}

\section{Within-population structure}

Our results suggest that Pholcus phalangioides populations are strongly influenced by genetic drift within small and demographically unstable mating units. Demographic instability within sites is suggested by six populations which show a significant higher $H_{\mathrm{e}}$ than expected at mutation-drift equilibrium. Genetic drift is supported by significant interpopulation differentiation. Even between adjacent sites the effect of drift can be considerable, suggesting that spider populations are, at least for a few generations, isolated from each other. Within populations, even in those collected from large corridors, no further subdivision could be ascertained, indicating that individuals migrate within buildings if possible. Although we are not able to separate the influence of these processes, both, single or by interaction, can cause the two-locus disequilibria (Hartl \& Clark, 1989) found in the present study. These two-locus disequilibria are, however, not confined to specific locus-pairs and populations, implying that the loci studied are probably unlinked and that demographic instability together with genetic drift appear to be general features shaping the population structure of $P$. phalangioides.

\section{Gene flow and geographical pattern of genetic subdivision}

Whatever the spatial scale investigated, gene flow seems to be insufficient to override the effect of genetic drift in $P$. phalangioides. Even within a single building genetic drift can result in significant interpopulation differentiation $\left(F_{\mathrm{XY}}=0.031\right)$. A lower degree of differentiation, for instance, was found in some free-living web spiders over distances of 30 and 100 kilometres (Boulton et al., 1998; Ramirez \& Haakonsen, 1999; but see also Ramirez \& Froehlig, 1997; Johannesen et al., 1998) and in some butterfly species over distances of several hundred kilometres (Eanes \& Koehn, 1978; Nibouche et al., 1998).

The allele frequency distribution of five variable allozyme loci showed significant genetic differentiation and isolation by distance among $P$. phalangioides populations over the area studied. Isolation by distance was found for three of the five polymorphic loci using a Mantel test and is also supported by autocorrelation analysis (Fig. 3), suggesting that the distribution of genetic variation is due to geographical separation rather than to natural selection, which is unlikely to affect different allozyme loci in the same manner. These results provide clear evidence for large-scale geograph- ical population structure in $P$. phalangioides. The presence of all main alleles over different regions demonstrates that long-distance gene flow is not sufficient to compensate for the effect of genetic drift caused by the geographical separation, but is strong enough to prevent fixation of alternative alleles over a distance of $917 \mathrm{~km}$. In $P$. phalangioides, passive transport rather than ballooning may promote gene flow even between distant populations.

Two-thirds of the total genetic variance was found within regions, and differentiation was shown to increase from the spatial level of the same building $\left(F_{\mathrm{XY}}=0.031\right)$ to that of the regional level $\left(F_{\mathrm{XY}}=0.096\right)$. However, no isolation by distance was found within a distance of $70 \mathrm{~km}$. Absence of any significant correlation between population differentiation and geographical distance does not necessarily reject isolation by distance because sample sizes and methods are limited (Peterson, 1996). On the other hand, isolation by distance cannot explain the high interpopulation variance in allele frequencies over this geographical range. These results support the idea that demographic instability in combination with genetic drift play a major role in determining the population structure in cellar spiders, causing significant, but unpredictable differentiation patterns at lower geographical scales. The lack of isolation by distance also suggests that the genetic exchange between less distant populations is restricted to the same extend than that between more distant populations. Thus, gene flow within urban regions seems to be limited by the ability to enter closed buildings and not by the general dispersal capacity of cellar spiders. These results suggest that the genetic structure in $P$. phalangioides is not supported by models of the stepping stone hypothesis, which assumes that gene flow is restricted to adjacent populations (Kimura \& Weiss, 1964).

\section{A comparison with other synanthropic species}

The estimate of genetic differentiation for another synanthropic pholcid spider Holocnemus pluchei (mean $F_{\mathrm{ST}}=0.116$ for five populations from California, Porter \& Jakob, 1990) is comparable to that found in $P$. phalangioides (mean $\theta=0.146$ ). The authors suggest that time was too short to produce further genetic differentiation, since $H$. pluchei, which originates from the Mediterranean region, was introduced into the United States during the early 1970s. As P. phalangioides is an original resident of central Europe, the comparable degree of differentiation between both species might be better explained by similar habitat requirements and dispersal behaviour than by the historical distribution pattern. 
Similar geographical patterns of population structure have been documented for house mice (Mus musculus domesticus), significant between-population division was noted, two-locus disequilibria were detected and within a distance of $60 \mathrm{~km}$ no significant isolation by distance was found (Dallas et al., 1998). However, BrittonDavidian (1990) found that population structure was roughly correlated with distance on a larger geographical scale. It can be assumed that buildings are confined habitats, restricting population growth and gene flow among subpopulations. Moreover, human influences of pesticide control, cleaning activities, seasonally limited nutrition availability, etc. can propagate demographic instability and hence, genetic drift effects. As a result, different synanthropic species might exhibit similar patterns of population structure.

In conclusion, our study revealed a high potential of dispersal in $P$. phalangioides, but populations are divided into small and demographically unstable mating units which are strongly affected by genetic drift. On a regional scale these processes seem to cause significant, but not stable genetic differences among cellar spider populations. Rates of dispersal decrease and become stable at distances between 70 and $180 \mathrm{~km}$, as indicated by a significant pattern of isolation by distance.

\section{Acknowledgements}

We thank J. Johannesen (Mainz), D. Tarkhnishvili, D. Heg, and K. Misof (all Bonn) for helpful discussions and comments on the manuscript. We also thank two anonymous referees for their critical reading of the manuscript. We are especially grateful to S. Toft, T. Bilde Kofoed, H. B. Jørgensen, K. \& B. Schäfer, H. Dick, M. Streif and A.O.E. Rasa for their contribution in collecting the spiders. The study was supported by the Deutsche Forschungsgemeinschaft (Uh87/2-1).

\section{References}

BOUlTON, A. M., RAMIREZ, M. G. AND BLAIR, C. P. 1998. Genetic structure in a coastal dune spider (Geolycosa pikei) on Long Island, New York Barrier Islands. Biol. J. Linn. Soc., 64, 83-99.

BRITTON-DAVIDIAN, J. 1990. Genic differentiation in $M . m$. domesticus populations from Europe, the Middle East and North Africa: geographic patterns and colonising events. Biol. J. Linn. Soc., 41, 27-45.

CESARONI, D., ALLEGRUCCI, G., CACCONE, A., COBOLLI SBORDONI, M. ET AL. 1981. Genetic variability and divergence between populations and species of Nesticus cave spiders. Genetica, 56, 81-92.

CORNUET, J. M. AND LUIKART, G. 1996. Description and power analysis of two tests for detecting recent population bottlenecks from allele frequency data. Genetics, 144, 2001-2014.
DALLAS, J. F., BONHOMME, F., BOURSOT, P., BRITTON-DAVIDIAN, J. ET AL. 1998. Population genetic structure in a Robertsonian race of house mice: evidence from microsatellite polymorphism. Heredity, 80, 70-77.

DECAE, A. E. 1987. Dispersal: Ballooning and other mechanisms. In: Nentwig, W. (ed.) Ecophysiology of Spiders, pp. 348-356. Springer Verlag, Berlin-Heidelberg-New York.

EANES, W. F. AND KOEHN, R. K. 1978. An analysis of genetic structure in the monarch butterfly, Danaus plexippus L. Evolution, 32, 784-794.

GOUDET, J. 1995. FSTAT, version 1.2: a computer program to calculate F-statistics. J. Hered., 86, 485-486.

HARRIS, H. AND HOPKINSON, D. A. 1978. Handbook of Enzyme Electrophoresis in Human Genetics. North-Holland Publishers, Amsterdam.

HARTL, D. L. AND ClARK, A. G. 1989. Principles of Population Genetics, 2nd edn. Sinauer Ass., Sunderland, MA.

HILliS, D. M. AND MORITZ, C. 1990. Molecular Systematics. Sinauer Ass., Sunderland, MA.

HUTCHINSON, D. W. AND TEMPLETON, A. R. 1999. Correlation of pairwise genetic and geographic distance measures: inferring the relative influences of gene flow and drift on the distribution of genetic variability. Evolution, 53, 1898-1914.

JOHANNESEN, J., BAUMANN, T., SEITZ, A. AND VEITH, M. 1998. The significance of relatedness and gene flow on population genetic structure in the subsocial spider Eresus cinnaberinus (Araneae: Erisidae). Biol. J. Linn. Soc., 63, 81-90.

KIMURA, M. AND WeISS, G. H. 1964. The Stepping Stone Model of population structure and the decrease of genetic correlation with distance. Genetics, 49, 561-576.

LOUIS, E. J. AND DEMPSTER, E. R. 1987. An exact test for HardyWeinberg and multiple alleles. Biometrics, 43, 805-811.

LUIKART, G., SHERWIN, W. B., STEELE, B. M. AND ALLENDORF, F. W. 1998. Usefulness of molecular markers for detecting population bottlenecks via monitoring genetic change. Mol. Ecol., 7, 963-974.

MANLY, B. F. J. 1991. Randomization and Monte Carlo Methods in Biology. Chapman \& Hall, London.

McCAULEY, D. E. 1993. Genetic consequences of extinction and recolonisation in fragmented habitats. In: Kareiva, P. M., Kingsolver, J. G. and Huey, R. B. (eds) Biotic Interactions and Global Change, pp. 217-233. Sinauer, Sunderland, MA.

NEI, M. 1978. Estimation of average heterozygosity and genetic distance from a small number of individuals. Genetics, 89 , 583-590.

NIBOUCHE, S., BUÈs, R., TOUBON, J.-F. AND POITOUT, S. 1998. Allozyme polymorphism in the cotton bollworm Helicoverpa armigera (Lepidoptera: Noctuidae): comparison of African and European populations. Heredity, 80, 438-445.

PETERSON, M. A. 1996. Long-distance gene flow in the sedentary butterfly, Euphilotes enoptes (Lepidoptera: Lycaenidae). Evolution, 50, 1990-99.

PORTER, A. H. AND JAKOB, E. M. 1990. Allozyme variation in the introduced spider Holocnemus pluchei (Araneae, Pholcidae) in California. J. Arachnol., 18, 313-319.

POULIK, M. D. 1957. Starch gel electrophoresis in a discontinuous system of buffers. Nature, 180, 1477-1479.

RAMireZ, M. G. AND Froehlig, J. L. 1997. Minimal genetic variation in a coastal dune arthropod: the trapdoor spider 
Aptostichus simus (Cyrtaucheniidae). Conserv. Biol., 11, 256-259.

RAMIREZ, M. G., HAAKONSEN, K. E. 1999. Gene flow among habitat patches on a fragmented landscape in the spider Argiope trifasciata (Araneae: Araneidae). Heredity, 83, 580-585.

RAYMOND, M. AND ROUSSET, F. 1995. GENEPOP (v.1.2.): Population genetics software for exact tests and ecumenicism. J. Hered., 86, 248-249.

RICE, W. R. 1989. Analysing tables of statistical tests. Evolution, 43, 223-225.

ROUSSET, F. 1997. Genetic differentiation and estimation of gene flow from $F$-statistics under isolation by distance. Genetics, 145, 1219-1228.

SACHER, P. 1983. Spinnen (Araneae) an und in Gebäuden Versuch einer Analyse der synanthropen Spinnenfauna in der DDR. Teil 2. Entomol. Nachrichten Berichte, 27, 141-224.

SELANDER, R. K., SMITH, M. H., YANG, S. Y., JOHNSON, W. E. ET $A L$. 1971. Biochemical polymorphism and systematics in the genus Peromyscus. I Variation in the Oldfield Mouse (Peromyscus polionotus).- Studies in Genetics IV. Univ. Texas Publ., 7103, 49-89.

SLATKIN, M. 1987. Gene flow and the geographic structure of natural populations. Science, 236, 787-792.

SLATKIN, M. 1993. Isolation by distance in equilibrium and non-equilibrium populations. Evolution, 47, 264-279.
SOKAL, R. R. AND JAQUEZ, G. M. 1991. Testing interferences about microevolutionary processes by means of spatial autocorrelation analysis. Evolution, 41, 152-168.

SOKAL, R. R. AND ODEN, N. L. 1978. Spatial autocorrelation analyses in biology I. Methodology. Biol. J. Linn. Soc., 10, 199-228.

SOKAL, R. R. AND WARTENBERG, D. E. 1983. A test of spatial autocorrelation analyses using an isolation by distance model. Genetics, 105, 219-237.

SWOFFORD, D. L. AND SELANDER, R. B. 1981. BIOSYS-1: $a$ FORTRAN program for the comprehensive analysis of electrophoretic data in population genetics and systematics. J. Hered., 72, 281-283.

VANUYTVEN, H. 1991. Spinnen in gebouwen in Belgié (Araneae). Nwsbr. Belg. Arachnol. Ver., 6, 15.

WARTENBERG, D. E. 1985. Spatial autocorrelation as a criterion retaining factors in ordination of geographic data. Math. Geol., 17, 665-682.

WEIR, B. S. AND COCKERHAM, C. C. 1984. Estimating $F$-statistics for the analysis of population structure. Evolution, 38, $1358-1370$

WHITLOCK, M. 1992. Temporal fluctuations in demographic parameters and the genetic variance among populations. Evolution, 46, 608-615.

Wright, s. 1978. Evolution and Genetics of Populations, vol. 4, Variability Within and Among Natural Populations. University of Chicago Press, Chicago. 